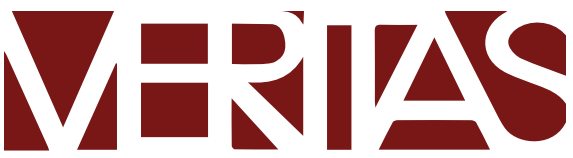

$\begin{array}{lllllllllll}P & O & R & T & O & A & L & E & G & R & E\end{array}$

http://dx.doi.org/10.15448/1984-6746.2019.2.32363

\title{
MIMESE, IDIOSSINCRASIA E INDÚSTRIA CULTURAL
}

Mimesis, idiosyncrasy and cultural industry

Mimesis, la idiosincrasia y la industria cultural

Sara Juliana Pozzer da Silveira'

Universidade Federal de Mato Grosso, Cuiabá, MT, Brasil.

\section{Resumo}

Ao tratar de diferentes aspectos do conceito de mimese na estética de Theodor Adorno, o artigo busca evidenciar a permanência do que Adorno designou como mimese primitiva ou originária na sociedade contemporânea. A análise do conceito de idiossincrasia servirá para mostrar esta permanência e, ao mesmo tempo, o seu reforço pela indústria cultural. Como contraponto a essa faceta do conceito de mimese, trataremos da mimese nos âmbitos científico, filosófico e no que Adorno considera obra de arte autêntica.

Palavras-chave: Mimese. Idiossincrasia. Indústria cultural. Filosofia. Ciência.

\section{Abstract}

In dealing with different aspects of the concept of mimesis in Theodor Adorno's aesthetics, the article seeks to highlight the permanence of what Adorno has desig-

1 Doutora em estética pela Universidade Federal de Minas Gerais. Professora do Curso de Filosofia da Universidade Federal de Mato Grosso, Cuiabá, MT, Brasil. http://orcid.org/ooooooo2-3758-1940. E-mail: sarapozzer@gmail.com 
nated as primitive or original mimesis in contemporary society. The analysis of the concept of idiosyncrasy will serve to show this permanence and, at the same time, its reinforcement by the cultural industry. As a counterpoint to this facet of the concept of mimesis, we will deal with the mimesis in the scientific, philosophical and in what Adorno considers an authentic work of art.

Keywords: Mimesis. Idiosyncrasy. Cultural industry. Philosophy. Science.

\section{Resumen}

Al tratar de diferentes aspectos del concepto de mímesis en la estética de Theodor Adorno, el artículo evidencia la permanencia de lo que Adorno llama de mimesis primitiva u originaria en la sociedad contemporánea. El análisis del concepto de idiosincrasia mostrará esta permanencia y, al mismo tiempo, su refuerzo en la industria cultural. Como contrapunto a esta faceta del concepto de mimesis se trata de mimesis en el nivel científico, filosófico y en lo que Adorno considera la obra de arte auténtica.

Palabras clave: Mimesis. Idiosincrasia. Industria cultural. Filosofía. Ciencia.

\section{Introdução}

$\mathrm{O}$ artigo pretende reler a noção de mimese na estética de Theodor Adorno evidenciando várias facetas desse conceito para mostrar que a primeira forma da mimese, originária, natural, própria da sociedade primitiva, constituída sob o poder dos rituais mágicos, está presente na sociedade contemporânea sob a forma da idiossincrasia. Mostraremos que as reações idiossincráticas são fundamentais para a realização do comportamento fascista o qual é, muitas vezes, reforçado pela indústria cultural. Para termos uma compreensão razoável dessa forma de mimese precisamos entender que, para Adorno, o conhecimento científico e o filosófico também são miméticos. Mas a mimese referente a esses âmbitos, limitada pela linguagem conceitual, é fonte restrita da expressão. Por isso, é preciso se deter na mimese própria à obra de arte, pois ela é tanto salutar para as insuficiências do conceito filosófico e científico quanto 
é um contraponto à mimese recalcada, expressa no comportamento idiossincrático da personalidade autoritária.

Para chegar a este resultado dividimos o artigo em quatro partes: na primeira, analisaremos brevemente as influências teóricas utilizadas por Theodor Adorno para construir o conceito de mimese e determinaremos a relação entre mimese e idiossincrasia; na segunda, trataremos da mimese como reflexão controlada, ou seja, a mimese presente nos conhecimentos científicos e filosóficos; e, na terceira, abordaremos a mimese na obra de arte como contraponto à mimese recalcada, presente no comportamento idiossincrático, também fundamental para a compreensão da noção de conhecimento filosófico proposto por Adorno. Na quarta parte, debateremos a relação entre o comportamento autoritário expresso na idiossincrasia e a confirmação desse pela indústria cultural. ${ }^{2}$

\section{Mimese e idiossincrasia}

O conceito de mimese em Theodor Adorno adquire sentidos diversos. Segundo Stein ${ }^{3}$, esses sentidos são construídos a partir de, pelo menos, três importantes influências que estariam na origem da construção do conceito. Primeiro, do antropólogo cultural francês Callois, para o qual o comportamento mimético é biológico e sociocultural - caracteriza-se pelo impulso de assimilação ao espaço, à identificação com o meio em que se vive. Em segundo lugar, tem-se a influência de Freud, e a sua noção de instinto de morte, que é interpretado por Adorno como sendo um determinante comportamental que, progressivamente, mimetiza a imobilidade, a morte. Essa noção freudiana aparecerá com bastante frequência na obra de Adorno, como veremos.

Em última análise, estão os escritos de Walter Benjamin, nos quais a arte se apresenta como uma riqueza inesgotável na produção de absurdos.

\footnotetext{
2 Todas as traduções, do espanhol, alemão e inglês, são nossas.

3 STEIN, (2008, p. 3-5).
} 
Stein usa um exemplo para explicar esta noção de mimese em Benjamin: ele fala da identificação na astrologia entre o macrocosmo e o microcosmo a qual, por mais absurda que seja, ainda revela algo da ânsia da busca pelo sentido. A influência de Walter Benjamin, talvez seja a mais difícil de precisar. Levaremos em conta essa influência recorrendo também a alguns escritos de Benjamim e de Gagnebin ${ }^{4}$. Esta autora nos mostra que para Benjamin a capacidade mimética humana não se manteve apenas na obra de arte, mas se refugiou na linguagem e na escrita. Tais noções influenciam a construção adorniana de que os conhecimentos científico e filosófico também são miméticos, que não há uma cesura definitiva entre mimese e racionalidade. Isso fica patente nos escritos tardios de Adorno, como a Dialética Negativa e Teoria Estética, mas já está presente, em traços gerais, na Dialética do Esclarecimento. ${ }^{5}$

Stein se refere a duas formas da mimese apresentadas na Dialética do Esclarecimento. A primeira, a mimese natural, seria realizada por animais e homens e é determinada por atitudes como fingir-se de morto para enganar a presa ou se assemelhar a uma planta ou animal com o mesmo intuito. Em segundo lugar, temos ainda a mimese originária só que pertencendo apenas aos homens. Na Dialética do Esclarecimento aparece a expressão mimese do amorfo [Mimikry ans Amorphe] ${ }^{6}$ que deve ser distinguida da mimese natural, porque nos seres autoconscientes ela é um modo inconsciente de reação ao poder ameaçador da natureza. Portanto, toda vez que nos referimos à mimese natural ou originária levaremos em conta essa distinção.

Como sabemos, para os autores da Dialética do Esclarecimento, o recalque da mimese natural não foi bem-sucedido no processo civilizatório. Isso tem implicações importantes no que diz respeito ao modo

\footnotetext{
4 GAGNEBIN (2014; 1993, p. 67-86) e BENJAMIN (2017)

5 Sigo aqui a posição de Albrecht Wellmer segundo a qual os principais temas da filosofia tardia de Adorno já estão presentes nas obras de juventude. Além disso, uma obra em especial, a Dialética do Esclarecimento traz em seu bojo os contornos dos principais temas que depois nortearão a Dialética Negativa e a Teoria Estética. Cf. WELLMER, (1993, p. 137, 151 e 153).
}

6 STEIN, (2008, p. 3). 
como Adorno pensará o comportamento do indivíduo em relação tanto à obra de arte autêntica quanto à indústria cultural. Um passo que nos parece fundamental para compreender esses momentos capitais da estética de Adorno é entender o conceito de idiossincrasia e a sua relação com a mimese originária. Ele é desenvolvido no capítulo "Elementos do antissemitismo" da Dialética do Esclarecimento.7 Para se ter uma ideia da importância desse conceito para os autores, basta lembrar que a compreensão da idiossincrasia, sua elevação à forma conceitual, levaria nada mais nada menos, que à compreensão do preconceito, do modo autoritário de atuação próprio às personalidades autoritárias, ou seja, a idiossincrasia é um conceito central para entender o funcionamento das mentes fascistas. ${ }^{8}$ No presente artigo, a compreensão da idiossincrasia terá como função mostrar que o primeiro sentido da mimese, a natural, pré-histórica, está presente na civilização, só que de modo recalcado.

A idiossincrasia é a lembrança recalcada das reações miméticas originárias, aquelas que foram reprimidas pela civilização: "Os motivos a que responde a idiossincrasia remetem às origens. Eles reproduzem os momentos da proto-história biológica: sinais de perigo cujo ruído fazia os cabelos se eriçarem e o coração cessar de bater" ${ }^{\text {" }}$. Seriam as reações compulsivas que remetem à proto-história biológica e que escapam ao controle do eu, ou seja, na ausência do contexto pré-histórico essas reações reaparecem porque certos órgãos se esquivam novamente ao controle do sujeito, "independentes obedecem a estímulos biológicos fundamentais"10. O comportamento mimético primitivo comportava dois tipos principais de reações: o escape da morte violenta fingindo-se de morto ou então procurando se identificar a alguma planta ou animal. Esse traço os autores constroem a partir de uma releitura da noção freu-

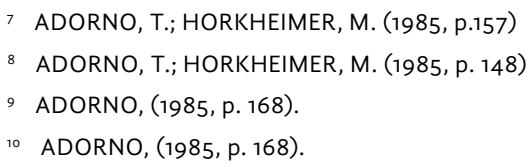


diana de impulso de morte, que é lida como um desejo de dissolver-se na natureza. O segundo tipo de reação é também de dissolução, mas agora não é por medo da morte, mas diz respeito a prazeres originários negados pela civilização, por exemplo, o prazer com o olfato, o fungar que pode lembrar nossa imersão no outro, no sentido da imediaticidade dos contatos. Assim, o prazer originário era também um tipo de prazer mimético dissolvente, no sentido de nos perdemos nas flutuações da natureza. Algo deste comportamento é mantido nas atividades lúdicas, principalmente das crianças. O mito de Dafne relido na Dialética do esclarecimento é simbólico em relação ao primeiro sentido aludido. Dafne para fugir da perseguição de Apolo (por ela perdidamente enamorado), para fugir do perigo, portanto, pede a seu pai para que seja transformada em uma planta, o loureiro. Desse modo, ela se dissolve na natureza ambiente tornando-se um vegetal. Portanto, o ato de identificar-se com a natureza ambiente, o perder-se nela em vez de controlá-la, comandá-la, significou tanto o extremo prazer quanto o extremo perigo da morte.

A tese dos autores é de que esse primeiro mimetismo não foi totalmente reprimido, ele ainda está presente na sociedade tecnológica contemporânea através de traços compulsivos inconscientes. Quanto menos bem-sucedida for a construção da identidade pessoal, responsável pela ordem lógica do pensamento, pela unidade e pelo sentido do mundo interno e externo, mais fraca é a individualidade e maior a possibilidade de reações idiossincráticas. Essa subjetividade fraca organiza penosamente a sua vida mental de modo que qualquer diferença àquela identidade construída pode gerar o mal-estar. É o típico comportamento da personalidade paranoide, que constrói sua imagem do mundo e não tolera nada diferente. Esse diferente, que não é tolerado, é o que foi reprimido com grande gasto libidinal. Assim, por exemplo, a reação dos racistas em relação aos negros pode desencadear reações repulsivas em relação a traços fisionômicos, não só a cor da pele, mas certos traços do rosto como o nariz mais achatado. Para explicar o caráter compulsivo 
dessas reações idiossincráticas Gagnebin" as compara à alergia ao pelo dos gatos ou à poeira. Elas operam como mecanismos de proibição que tentam impedir a recordação, não só do medo da morte, mas do prazer com os contatos mais imediatos, com o perder-se na natureza externa e no envolvimento com os outros.

Como é sabido, na Dialética do Esclarecimento o processo civilizatório é compreendido como um processo lento em que se mostra a contínua negação da mimese natural, incontrolada. A formação do ego é uma espécie de contínuo enrijecimento contra a dispersão, ou seja, contra o abandono. "Toda diversão, todo abandono, tem algo de mimetismo. Foi se enrijecendo contra isso que o ego se forjou." ${ }^{\prime 2}$ É através de sua constituição que se realiza a passagem da mimese refletora para a reflexão controlada. A assimilação física da natureza é substituída pela recognição no conceito, a compreensão do diverso sob o mesmo, o idêntico"13.

Vamos entender primeiramente o que seria a mimese como reflexão controlada, a insuficiência desse modelo de mimese para a reflexão filosófica e de como a mimese própria à obra de arte é tanto salutar para as insuficiências do conceito quanto é um contraponto à mimese recalcada, expressa no comportamento idiossincrático do paranoico.

\section{Mimese como reflexão controlada}

Adorno pensa a recognição tendo em mente a noção kantiana do ato de conceitualizar o qual significa julgar, subsumir o diferente à regra previamente estabelecida pelo intelecto. Mas porque isto seria a continuação da mimese arcaica? A teoria quer identificar-se com a natureza ambiente, tornar a natureza comensurável a ela, ou seja, ainda é a tentativa de se identificar com a natureza para preservar-se, só que identificando a

\footnotetext{
1 GAGNEBIN (1993, p. 74).

ADORNO, (1985, p. 169).

13 ADORNO, (1985, p. 149).
} 
teoria à natureza. Poderíamos dizer, em um sentido bem genérico, que a natureza é a projeção de nossos conceitos e categorias. Libertamos-nos do poder da natureza sobre nós a dominando. Mas Adorno e Horkheimer dizem que este nosso domínio é ainda a continuação da nossa submissão à natureza. É falsa a autocolocação do espírito como separado da natureza, a razão inatural de Kant, por exemplo, a qual precisa ser um pressuposto transcendental, nem natural, nem transcendente.

Para clarificarmos essa noção de mimese como recognição e a sua gradual "evolução" no processo civilizatório precisamos ter em mente dois momentos deste processo: a) a mimese natural que significava tentar tornar-se semelhante à coisa no ato cego de viver tanto em função do medo da morte quanto pelo abandono ao prazer, aspecto já comentado acima; e b) a identidade não mais imediata da mimese, mas a identidade mediata da síntese.

A síntese conceitual foi o médium que se estabeleceu entre homem e natureza. Dizer: a natureza deve ser dominada pelo trabalho, também significa dizer: e significada pelo conceito, ou seja, ela também é apropria$\mathrm{da}$, dominada pela linguagem. A autonomização da linguagem em face dos processos naturais para poder manipulá-los começou com os rituais religiosos e teve seu ápice na ciência moderna com a formalização do pensamento. Para que os projetos científicos sejam utilitários e inventivos é preciso: definição rigorosa de conceitos, delimitação clara do método, ou seja, a delimitação de um "campo a ser investigado em seus menores detalhes sem que o investigador o transcenda".14

Como o comportamento mimético é um comportamento natural, os autores falam várias vezes que o espírito é o prolongamento da natureza e não a oposição a ela. A separação sujeito/objeto através da qual o eu é posto como acima da natureza e se torna "máscara impenetrável" é, na verdade um pedaço de natureza disciplinada, "espiritualizada". ${ }^{15}$ Isto quer dizer que o ápice da formalização na ciência ainda é parte do com-

\footnotetext{
14 ADORNO, (1985, p. 161).

15 ADORNO, (1985 p. 43 e 53 ).
} 
portamento natural, a demarcação do campo e o rigor das definições. Tal comportamento é uma espécie de projeção do sujeito que quer que a teoria se identifique com a natureza. Para Adorno todo juízo tem um caráter assertivo ${ }^{16}$ mesmo o negativo, o asserir traz intrinsicamente consigo a pretensão de verdade e, portanto, de identidade.

Se levarmos ao pé da letra o que Adorno diz é como se a natureza cindisse a si mesma quando da formação do espírito, assim este não é mais do que uma das funções da autoconservação dos indivíduos e da espécie. Mas quando o espírito se considera a esfera das puras idealidades, seja o sujeito transcendental, seja a esfera lógica, ele se esquece de suas origens, ou seja, de que também é o pedaço de natureza que falávamos. Esse esquecimento se efetua, portanto, como formalismo e o ápice desse é a utilização da matemática na experimentação científica. A matemática é uma forma altamente refinada do mimetismo enquanto assimilação do pensamento ao imóvel. ${ }^{17}$ Ou seja, enquanto assimilação do pensamento ao que está morto. Também aqui os autores falam em "mimese da morte" porque não se trata da natureza viva em sua multiplicidade, mas da natureza como substrato neutro a ser quantificável, ou seja, a natureza é aquilo que pode ser quantificado, inclusive o que não se encaixa, a irracionalidade e indecibilidade devem se acomodar aos teoremas matemáticos ou serem excluídos. Se o modelo científico for o único lugar da verdade, o próprio eu, o corpo, a vida social torna-se este substrato a ser quantificável, a sociedade se converte em um sistema de funções e os homens em objetos manipuláveis. Isto significa que é preciso outros modos de se pensar a racionalidade para que todos os âmbitos da vida não sejam substratos neutros a serem significados pelas teorias matemático-científicas.

A filosofia é o espaço que tematiza o todo para além apenas dos campos determinados das ciências particulares. O lugar da filosofia nesse contexto fica mais claro se levamos em conta o que os autores dizem sobre

\footnotetext{
16 ADORNO, (1985, p. 160).

17 ADORNO, (1985, p. 150).
} 
a percepção. Esta só é possível na medida em que o objeto já é percebido como determinado, ou seja, como já pertencendo a certa classe de objetos. Nesse sentido "ela é a imediatidade mediatizada, o pensamento com a força de sedução da sensibilidade." ${ }^{18}$ Nesta aparente "autodoação" do objeto na percepção são introduzidos cegamente projeções subjetivas. "Só o trabalho do pensamento, consciente de si mesmo, consegue escapar a esse poder alucinatório, e, segundo o idealismo de Leibniz e de Hegel, a filosofia." ${ }^{19}$ Quer dizer, a filosofia é o conhecimento capaz de não se iludir com a possibilidade de um conhecimento imediato, como se fosse possível determinar o objeto para além da mediação do conceito, ou seja, ela é consciente da defasagem entre o que dizemos do mundo e como este é em si mesmo. Apesar disto, também a filosofia, como todo conhecimento, tem em si o elemento mimético. Como entender?

Adorno chega a esse resultado em função de sua luta por superar o idealismo de Kant e Hegel. Se por um lado, a proposta kantiana de superação da metafísica ao instituir os limites do conhecimento ao âmbito bem humano do sujeito transcendental, fez época contra o dogmatismo, por outro, ela encerraria o objeto nos estreitos limites da lógica transcendental tal como construída na Crítica da Razão Pura. Por mais que Adorno refira-se a uma primazia do objeto, já presente em Kant, devido ao peso dado à experiência nesta filosofia, as categorias e princípios através das quais o objeto é constituído são fixas o que não possibilita que se veja para além dos limites que estes elementos determinam. Não vamos aqui reconstruir toda argumentação de Adorno pró e contra Kant e Hegel, pois isto extrapolaria todos os limites deste trabalho. Queremos apenas mencionar a aceitação da noção de mediação recíproca de Hegel, pois ela será fundamental para reconstruir a filosofia sem que seja com uma base transcendente ou transcendental. Para Adorno, Hegel radicaliza a noção kantiana de que a unidade do conceito é a unidade do sujeito, na

\footnotetext{
18 ADORNO,(1985, p. 180).

19 ADORNO, (1985, p. 181).
} 
medida em que pensa a unidade sintética do discurso e a apercepção sintética kantiana, o eu penso transcendental, como total, e nessa totalidade princípio do ser e do pensamento. Nesse processo o sujeito do pensamento não pode ser hipostasiado como autocrático e separado do processo, o constituindo, porque ele também, afetado pelo espaço tempo, é fenômeno. Assim, o sujeito afetado pelo objeto se modifica. É a possibilidade de pensar que as categorias e princípios que fundamentam o discurso podem se mover a partir da relação com o objeto. Isto possibilitaria que o novo fosse expresso no processo do pensamento. Além disso, quando o sujeito deixa de ser o fundamento e o objeto é não somente um extrato assignificativo a ser constituído, mas a instância capaz de mover os conceitos do sujeito, temos a primazia do objeto. Entretanto, isto não rompe com as limitações às pretensões metafísicas postas pela Crítica da Razão Pura, pois continuamos não conhecendo o objeto como é em si mesmo. Adorno não crê que possamos ter um conhecimento dos objetos independente da mediação do conceito.

Saber que o objeto vem antes do sujeito não é o mesmo que ter conhecimento imediato de um objeto. Adorno não duvida nem por um segundo que o conhecimento dos objetos é conceitualmente mediado, e que na atividade cognitiva real a concessão à primazia do objeto implica a 'distinção qualitativa progressiva' das coisas mediadas, não um além, mas um momento dentro da dialética e não além dela ${ }^{20}$.

Com a possibilidade de pensar o movimento das formas do sujeito trazido com o conceito de mediação, Adorno passa a atribuir ao sujeito o papel não mais de constituir o mundo, mas de fazer experiência no sentido de que o papel central do sujeito não está na forma, como Kant supunha, mas na experiência. Esta tem como característica central a transformação e o que transforma o sujeito é seu encontro com o que não é, o que vai

20 BERNSTEIN, (2006, p. 114). 
além de sua antecipação e de sua suposta autoridade legal. Entretanto, assim como o sujeito transcendental, uma entidade lógica, é incapaz de fazer experiência, também o conceito hegeliano não o é. Mesmo que se fale em "vida" do conceito, para Adorno são somente os sujeitos individuais situados e datados que são capazes de fazer experiência.

Um sujeito com essas habilidades não é mais o sujeito do idealismo: é um sujeito vivo que, em seu ser como sujeito, é também um objeto no meio de objetos. Como esse sujeito naturalizado, vivido, opera e a atividade é um modo de se tornar, o sujeito vivo não pode ficar de fora da história... Isto é suficiente para argumentar que uma vez que o imponente conceito de identidade derivado da história natural e das relações de troca é removido do idealismo de Kant e Hegel, ele começa a assumir a fisionomia de uma futura filosofia materialista ${ }^{21}$.

A famosa divisa da Dialética Negativa de chegar ao não conceitual através do conceito, é o resultado de toda esta discussão com os modernos. Ela pretende expressar a possibilidade de uma síntese não violenta, ou seja, que consiga o sentido, a unidade, sem enquadrar a multiplicidade em um esquema prévio. Esse conhecimento ainda tem algo de mimético porque, tal como os outros, pretende manter a síntese, a unidade. E toda pretensão de síntese (como já dissemos) é assertiva na medida em que traz consigo a pretensão de verdade, de que a teoria e o mundo devem coincidir. Mas essa mimese do conceito filosófico vai ser tratada de modo especial, na medida em que Adorno recorrerá à mimese própria da obra de arte para que a filosofia chegue à síntese sem violência. Quer dizer, a tentativa é mostrar que filosofia e arte conseguem construir pontes para o real, sem enquadrá-lo previamente em uma linguagem formalizada. Aqui opera muito mais a noção de mimese benjaminiana que pensa a linguagem como configuração do real do que a noção kantiana de constituição.

${ }^{21}$ BERNSTEIN, (2006, p. 117). 


\section{Mimese e racionalidade na obra de arte}

A mimese da arte é uma atividade cognitiva racional e não a recaída na mimese arcaica. No contexto estético temos tanto o aspecto identificador da racionalidade quanto os impulsos miméticos.

Adorno desde a Dialética do Esclarecimento até à Teoria Estética fala que a lógica da obra de arte autêntica não é a simples continuação da lógica do processo social. É importante entender como Adorno compreende a diferença entre essas duas lógicas, pois assim também compreenderemos a característica central da estética de Adorno, que é a manutenção da possibilidade da conceitualização do que seja obra de arte em relação a outros tipos de objetos. Claro que este é um problema amplo e nos restringiremos àquelas considerações teóricas que nos ajudarão a compreender a noção de obra de arte autêntica em relação à mercadoria cultural e à regressão, temas do nosso próximo "subcapítulo". Na Teoria Estética Adorno fala que a lógica interna das obras como que enfrenta a lógica discursiva que também é vista como a lógica do sistema social, tal como tratada na Dialética do Esclarecimento. Também, nessa obra, já está expresso que a organização lógica do pensamento é correlativa ao modo como a sociedade se organiza. Então, aquela identidade entre o sujeito e a síntese linguística do idealismo é pensada no contexto de uma história natural. Assim, tanto a unidade que mantém a coerência do discurso cotidiano quanto a do discurso científico obedecem às regras lógicas historicamente constituídas. Desse modo, a tese adorniana de que esse modelo de linguagem sintética, na medida em que é a expressão da dominação sobre a natureza e os homens, é eficiente sob o ponto de vista da produção científico-tecnológica, mas não consegue expressar as diversas dimensões das vivências humanas tem o seu contraponto na lógica da obra de arte na medida em que esta seria capaz de expressar aquele para além do conceito de que fala a Dialética Negativa ${ }^{22}$.

${ }_{22}$ ADORNO,(2009). 
A mimese da obra de arte, ao contrário da cognitiva, não é a projeção de um conjunto de elementos linguísticos sobre a realidade visando à identificação entre teoria e fenômeno. A mimese que permanece na obra de arte tem algo da primeira forma da mimese, a originária. Por isso, Adorno fala em impulsos miméticos. Essa natureza que não foi totalmente reprimida pela lógica da síntese é a que retorna em cada nova obra de arte. O desafio na estética de Adorno é entender como se entrecruzam os impulsos miméticos e a lógica da síntese na obra de arte. A rigor, só existe uma lógica com seus princípios e conceitos fundamentais que cotidianamente usamos. Na obra de arte esta lógica é como que subvertida. Adorno aceita de Kant a noção de livre jogo, no seguinte sentido: é certo que ele pensa que o sujeito transcendental é uma hipostasiação indevida, como vimos, mas na Teoria Estética ele também elogia Kant por esse ter retirado a arte do terreno do "filisteísmo" vulgar que volta a tocá-la com a indústria cultural ${ }^{23}$. Ou seja, ele elogia o fato de Kant pensar o terreno do estético independentemente do terreno da culinária, da satisfação de projeções subjetivas singulares imediatistas. Como sabemos, o jogo livre que para Kant é produzido com a importante função da imaginação produtiva não determina os objetos, mas conduz a um conhecimento geral no sentido de que o terreno do estético não é independente das regras da lógica, mas que joga livremente com elas. Como dissemos, algo disso está presente na estética de Adorno na medida em que a lógica da obra subverte a lógica "normal". Na interpretação de Stein o poder de síntese reconhecido por Adorno na racionalidade estética, o momento de organização da obra de arte, consegue compatibilizar coisas incompatíveis porque a síntese na obra de arte não é apenas o conjunto dos elementos, mas o que eles comunicam entre si. "Constelações que não se conectam arbitrariamente de acordo com a especificação do sujeito, mas a verdadeira fantasia sintetiza aquilo que a síntese também permite e exige de si". ${ }^{24}$

\footnotetext{
23 ADORNO, (2004, p. 21).

24 STEIN, (2008, p. 6).
} 
Aqui, mesmo que Stein não mencione, nos parece que está implicitamente referindo-se a um momento central da Teoria Estética, quando Adorno fala que nas obras de arte não há a separação, presente no conhecimento, entre em-si e para-si, entre sujeito e objeto. Sendo a forma estética conteúdo sedimentado, a organização dos materiais, dos diversos elementos que participam da obra de arte não se dá como uma organização ideal do conteúdo, ou seja, não temos um espírito subsumindo um conteúdo dado a sua forma. Então, poderíamos dizer, no espírito kantiano, que não há uma forma sintética subsumindo estes diversos elementos, mas arranjo deles de tal forma que não há problemas se esta organização não usa a lógica da síntese de modo usual. Entretanto, na estética de Adorno, há algo mais que isso, porque Adorno insiste na primazia do objeto também aqui, na medida em que desse rearranjo dos elementos na obra pode surgir algo totalmente novo para os padrões cognitivos e que escapa à intenção do próprio artista. Isto é possível devido aos impulsos miméticos de natureza inconsciente. É como se as obras pudessem expressar algo do "em si", totalmente incognoscível em Kant. Entretanto, Adorno não recai no realismo pré-crítico porque esse em si, que se apresenta, fala como as fadas nos contos: "Queres o incomensurável? Terás, só que incognoscível"25. Albrecht Wellmer interpreta esse momento "truncado" da estética de Adorno da seguinte forma: "Na arte, o mimético adota a figura do espírito, na Filosofia, o espírito racional se atenua convertendo-se em mimético e conciliador"26. Quer dizer, há uma insuficiência em ambas que acaba complementando-as. A linguagem da síntese através da filosofia almeja dizer o absoluto, reconciliar a fenda entre imagem e conceito, mas como a razão não ultrapassa seus limites isso é impossível, na arte, em certos instantes, parece que o absoluto se apresenta, mas tal como aparece se obscurece tal como uma luz excessiva não deixa o olho ver. Esse caráter insuficiente, que torna as duas formas de expressão

\footnotetext{
25 ADORNO, (2004, p. 172).

26 WELLMER, (1993, p. 151.)
} 
incapazes de dizer o absoluto, é também pensado por Adorno como sendo a expressão da própria realidade deformada do capitalismo tardio, ou seja, a totalidade social é a falsa reconciliação entre o universal e o particular. Por isso, a filosofia de Adorno não será sistemática, mas fragmentária assim como a arte moderna. A noção de verdade como reconciliação é uma espécie de ponto de fuga onde a teoria pode se situar para poder pensar a irreconciliação entre linguagem e mundo. Como ponto de fuga, ela não é positivada, permanece como um ideal.

O fechamento monadológico das obras de arte por causa da logicidade imanente (que lhes é singular) e dos impulsos miméticos (inconscientes), portanto, auxilia a razão filosófica a ver algo para além da síntese. Com isto, Adorno pretende ter concebido um modelo de conhecimento onde se entrecruzam diferentes dimensões do conceito de verdade: assertiva, sintético cognitiva, prática, no sentido da reconciliação. Por isso, Wellmer afirma que já está na Teoria Estética de Adorno algo que era concebido como se tivesse vindo só depois com a filosofia pragmática da linguagem:

Ora, o próprio Adorno sempre enfatizou a inter-relação das várias dimensões da verdade na verdade artística; isso encontra expressão tanto na ideia de associação do mimético-expressivo com um momento racional na obra de arte, quanto em sua conceituação da relação entre verdade, aparência e reconciliação. A interpretação da verdade da arte em termos da interação entre as várias dimensões da verdade é, nesse sentido, inicialmente apenas uma reformulação linguístico-pragmática de um pensamento central para Adorno ${ }^{27}$.

Adorno vê na arte moderna a fragmentação em oposição à sistematização do discurso funcional da ciência. Ele dá uma grande importância ao caráter construtivo individual que considera como um desvincular-se cada vez mais do indivíduo produtor de arte dos esquemas tradicionais

27 WELLMER, (1984, p. 106). 
da composição. Assim, tanto a obra quanto a individualidade são avessas à sistematização. Este "eu" visa livrar-se da coerção social internalizada. $\mathrm{Na}$ obra dedicada a Kafka ${ }^{28}$, em certo momento, Adorno compara Freud e Kafka no que diz respeito ao fim da substancialidade do eu. Isto fica claro se pensamos em uma obra famosíssima de Kafka, A Metamorfose ${ }^{29}$. Essa obra mostra o fim de um padrão referencial seguro sobre o viver, tanto em termos da individualidade interna quanto em relação ao meio que o cerca. No decorrer da obra, o personagem central, Gregor, deixa de ser tratado como um eu [er] para ser tratado como um objeto [es], à medida que ele não é mais o filho querido que provê o sustento da família, mas o inseto que só estorva. Então, temos a crítica à aparência social das relações familiares, mostrando sua falsidade e irreconciliação, mas esta crítica não se apresenta através da lógica da síntese, mas através da introdução dos elementos miméticos, do insensato, fictício etc. Desse modo, é como se a arte moderna liberasse a individualidade do constituir-se a partir de padrões rígidos de comportamento. É essa capacidade de receber o difuso e cindido que marcará a diferença entre as obras de arte autênticas e a padronização da indústria cultural.

\section{Mimese, paranoia e indústria cultural}

Na Teoria Estética, Adorno afirma que antes da lógica do mercado adentrar o terreno da cultura com a indústria cultural, o indivíduo que contemplava, escutava ou lia uma obra precisava esquecer-se de si mesmo para abandonar-se à obra ${ }^{30}$. Para explicar como era a identificação com a obra Adorno retoma de Hegel a noção de "liberdade perante o objeto"31. Ele não projetava na obra meramente as suas aspirações. Tal como na

\footnotetext{
28 ADORNO, ( 2001, p.p. 239-271).

29 KAFKA, (1997).

30 ADORNO, (2004, p. 30-31).

31 ADORNO, (2004, p. 364).
} 
"Fenomenologia do Espírito" o sujeito sai de si e se "perde" no objeto para retornar mais enriquecido em termos de experiência. Com a indústria cultural e a exigência de que as obras sejam "tábua rasa" de projeções subjetivas, o contemplador percebe o "eco estandardizado de si mesmo nas obras"32.

Na Dialética do Esclarecimento, o esquematismo é pensado apenas como mera analogia ao kantiano, pois aqui não se trata de esquematismo transcendental, os autores dizem que a indústria cultural esquematiza as percepções das pessoas na medida em que o mundo passa a ser percebido através de seus esquemas, uma espécie de filtro. Estes são os padrões presentes nestas obras, clichês, fórmulas de sucesso etc. Mas, o planejamento do esquematismo da indústria cultural, o modo como esses produtos devem ser para conquistar os consumidores, não é simplesmente infligido por ela, mas é "imposto pela sociedade que permanece irracional apesar de toda racionalização"33. Quer dizer, a padronização das obras segue parâmetros advindos da sociedade que "permanece irracional", isto é, continua sendo comandada pelo anonimato do mercado.

Com a padronização das obras ocorre a liquidação da dialética entre o todo e o detalhe. Assim, a sequência de um filme comercial, por exemplo, já nos é familiar desde o início do filme, pouco importa os detalhes que serão inseridos na fórmula. Eles são fungíveis, podem ser trocados por outros. $\mathrm{O}$ contrário ocorre na obra de arte autêntica, onde o todo e o detalhe exibem uma relação intrínseca. O universal que está presente nessas obras é o social, que se sedimenta no estilo. Nesse, era mantida a tensão entre o sedimento social na obra e a particularidade, expressão dos impulsos miméticos do artista.

Se é que dá para falar de estilo na indústria cultural, o universal é calculado no esquema geral do sucesso e o particular é substituível, como dissemos. Mas aqui é preciso notar que está presente o elemento da censura. Essa ocorre de modo indireto. Ao adaptar Mozart ao jazz, perdemos aquilo que caracteriza o primeiro como único, o mesmo ocorre ao adaptarem-se

\footnotetext{
32 ADORNO, (2004, p. 31).

33 ADORNO,(1985, p. 103).
} 
as narrativas tradicionais do conto de fadas à fórmula do filme Disney, por exemplo. A obra é podada, limitada, para caber no jargão ${ }^{34}$. Entretanto, a repressão maior não se dá em termos diretos. A censura está no fato de que o desejo nunca deve ser satisfeito. Devemos nos contentar com a leitura do cardápio, pois a refeição nuca virá. Nesse sentido, os autores afirmam que a indústria cultural repete o ritual de Tântalo. Tudo nos é oferecido e, ao mesmo tempo, retirado. Por exemplo, ela está sempre expondo a sexualidade, mas "a produção em série do objeto sexual produz automaticamente o seu recalcamento"35, ou seja, pode-se ser até libertino, desde que se siga o estereótipo da tela. Assim, ela organiza os impulsos "primitivos" como a sexualidade ou mesmo a impulsividade destrutiva, e as pessoas cedem à sedução mimética, mas da forma como a indústria cultural propõe, não espontaneamente. Por isso, no fundo, apesar de todas as "novidades" os consumidores são os mesmos logrados de sempre.

Em um momento histórico de amplo crescimento técnico-científico, portanto, o que se vê não é a autonomia dos indivíduos, mas a redução desses a material: como clientes e empregados ${ }^{36}$. O indivíduo que projeta sobre a realidade um comportamento estandardizado que recebeu dela pode se apresentar como "o homem de bem", mas a possibilidade da expressão de alguma autenticidade própria (relações humanas espontâneas e diretas), se é que ainda a tem, é vedada, por isso ele já é virtualmente o nazista ${ }^{37}$. Ele não consegue nem se abandonar à grande arte porque essa, por não ser estandardizada, sempre traz elementos que geram o estranhamento e para a personalidade autoritária tudo deve se encaixar no seu esquema mental. Além disso, a grande arte, ao exigir esforço e concentração, colide com o desejo de não fazer esforço algum, presente na maioria das pessoas depois do tempo de trabalho sob a pressão do capitalismo. Mas ele tam-

\footnotetext{
34 ADORNO, (1985, p. 106).

35 ADORNO, (1985, p. 115).

36 ADORNO, (1985, p. 121).

37 ADORNO, (1985, p. 129).
} 
bém não consegue se abandonar àquilo que os autores chamam de o puro entretenimento, que seria o "abandono descontraído à multiplicidade das sensações e ao absurdo feliz" ${ }^{\prime 3}$, pois isso também implica em abandonar os esquemas fixos do como a vida deve transcorrer.

A pessoa não paranoica consegue discernir entre o mundo interior que é projetado e o exterior: "a distinção ocorre no sujeito que tem o mundo exterior na própria consciência e no entanto o conhece como outro"39. Como já dissemos, todo juízo, mesmo o negativo, assere algo, tem algo de paranoico na medida em que a noção de pretensão de verdade está sempre presente, mas ao formular o juízo "sabemos" da distinção juízo-mundo. $O$ paranoico mantém uma espécie de excessiva coerência no pensamento:

Ao invés de elaborar intelectualmente o fracasso da pretensão absoluta e assim continuar a determinar seu juízo, o paranoico se aferra a pretensão que levou seu juízo ao fracasso. Ao invés de prosseguir penetrando na coisa, avaliando seu juízo, o pensamento inteiro se põe desesperadamente a serviço do juízo particular ${ }^{40}$.

Segundo os autores, a paranoia é a sombra do conhecimento. Enquanto nesse, para que o resultado seja correto e eficiente, o investigador precisa definir rigorosamente os conceitos e delimitar um campo de investigação sem que ele possa transcender esse campo, assim também o paranoico não consegue deixar de transgredir um complexo de interesses determinados por seu "destino psicológico"41. Entretanto, diferente do paranoico, o cientista mantém a defasagem entre teoria e mundo, de modo que, em caso de falha, ele refaz a teoria, ou seja, o espaço para a dúvida é mantido.

\footnotetext{
38 ADORNO, (1985, p. 117).

39 ADORNO, (1985, p. 156).

40 ADORNO, (1985, p. 160).

${ }^{41}$ ADORNO, (1985p. 161).
} 
Assim, esse eu que projeta compulsivamente "não pode projetar senão a própria infelicidade cujos motivos se encontram dentro dele mesmo, mas dos quais se encontra separado em sua falta de reflexão"42. Os impulsos inconscientes que são uma ameaça constante à subjetividade, ao equilíbrio psíquico, são, sob a pressão do superego, projetados no grupo ou indivíduo considerado outsider. Ao projetar os impulsos proibidos no grupo escolhido como outsider é como se os sublimasse. A fúria contra o outro, o desejo de destruição é porque esses satisfariam aquilo que ele não pode. Essa sublimação adquire diversos contornos, como por exemplo, o de legítima defesa. Essa é exemplificada no comportamento desses indivíduos quando usam como justificativa para suas ações destrutivas a necessidade de salvar a família, a pátria etc.

O paranoico não pode buscar na análise e aprofundamento de seus juízos em relação à realidade a verdade, então ele busca na confirmação de outros paranoicos. Por isso a humanidade ainda parece viver, sob certos aspectos, como constituída por um conjunto de hordas: "os grandes impérios, e até mesmo a humanidade organizada como um todo, não estão nem um passo à frente dos caçadores de cabeças"43. É nesse contexto que a idiossincrasia, tratada no início de nosso trabalho, aparece. As pessoas paranoicas só se apercebem de seus traços miméticos, que são tabus inconscientes que devem ser reprimidos, no comportamento dos outros, daqueles que serão os outsiders. São os traços de algo que está neles mesmos e que não podem admitir. Por isso, Adorno afirma, na esteira de Freud, que "o que repele por sua estranheza é, na verdade, demasiado familiar."44 $\mathrm{O}$ trágico de tudo isso é que como as reações idiossincráticas são inconscientes, elas são compulsivas e, como o paranoico não se apercebe que seu juízo pode não condizer com a realidade, é muito difícil de mudar esse comportamento.

\footnotetext{
42 ADORNO, (1985p. 161).

43 ADORNO, (1985, p.183).

44 ADORNO, (1985, p. 150).
} 
A indústria cultural ajuda a alimentar a paranoia porque a imaginação produtiva é substituída pela recepção e a experiência é substituída pelos clichês e fórmulas de sucesso. Nesse sentido, através do clichê, o paranoico busca nas obras da cultura de entretenimento a confirmação de sua posição, ou seja, poderíamos dizer no espírito kantiano, que não temos a imaginação produtiva operando porque o que é buscado são os comportamentos estereotipados que já confirmam os esquemas mentais. O contemplador percebe "o eco estandardizado de si mesmo nas obras". ${ }^{45}$ Então, a função da mimese aqui é mais a de expressar os impulsos recalcados do que a reconciliação, ideal da mimese autêntica da grande obra de arte. Quer dizer, enquanto na obra autêntica, a imagem de um monstro, por exemplo, na medida em que pode ser contemplada, é uma espécie de reconciliação com o medo primitivo da morte violenta, no filme de ação comercial, o monstro na tela pode ser a projeção do desejo de matar e da satisfação fascista na destruição do outro. Para explicar isso, tomo a liberdade de me reportar a uma experiência pessoal. Refiro-me a uma passagem do trailer do novo filme Venom, personagem maléfico nos filmes do homem aranha. A cena mostra o seguinte: Venom, que tem o poder de se apoderar do corpo das pessoas, aparece em uma lanchonete na figura de um homem comum, branco e musculoso. Na lanchonete estão presentes a funcionária e outro cliente, por sinal, um chinês, representado como um homem comum, um tanto acanhado. $O$ homem branco se transforma no monstro Venom, e devora o chinês sob o olhar assustado da garçonete. Logo em seguida, ele volta à forma humana, sorri e diz algo como: estava na hora do lanche! Notei que o público no cinema riu. Isto é para ser uma piada! Devorar, destruir o outro é motivo de riso. $\mathrm{E}$ aqui, como estudante da filosofia de Adorno, fico em uma encruzilhada: por um lado, é apavorante a ideia de que as pessoas sentem prazer com a destruição do outro; por outro, como quem devora é o monstro, esse

45 ADORNO, (2004, p. 31). 
prazer estaria sublimado na tela. Neste ponto nos vem à mente o famoso debate entre Adorno e Benjamin sobre a função do cinema. Sabemos da dimensão desse tema e sabemos que não cabe nos limites do trabalho. Limitaremos-nos a algumas notas que visam clarificar nosso embaraço em relação à cena referida. Sob o ponto de vista de Benjamin resgataríamos a função catártica do filme, em vez de sair por aí pilhando e matando os outros, eles se satisfazem com o que Venom faz na tela. A noção de "espaço de jogo" construída por Benjamin para ressaltar o caráter de montagem da obra fílmica nos auxilia a conviver com o choque decorrente da vida sob uma sociedade tecnizada, técnica essa que não dominamos, que permanece estranha. Conviver com o monstro na tela nos ensina a conviver com nossos monstros no cotidiano tecnizado. ${ }^{46}$

Vejamos que, sob o prisma da estética de Adorno, não temos nessa cena a conciliação com o impulso destrutivo inconsciente porque é para rir com a destruição do outro, ou seja, essa gargalhada é resultado da aniquilação daquele que é considerado inferior e que mobiliza elementos idiossincráticos inconscientes. A função catártica está em sentir que Venom está acima do direito, porque enquanto superpoderoso, ele pode devorar quem ele quiser, especialmente esses tipos reles, descartáveis, fracos, que é como o chinês aparece ali. Ou seja, a função catártica não está em contemplar o monstro a distância conciliando nossas pulsões em relação ao medo da morte, ou então sublimando os impulsos destrutivos na satisfação na destruição cometida pelo monstro, mas na piada grotesca de que ele está fazendo um lanche. Parece não haver nenhum dilema ético nas pessoas que riem com esse tipo de cena. Isso leva a pensar no que ocorreria se o direito não impedisse a busca da satisfação do desejo destrutivo? Por que continuar indo ao cinema para satisfazer o proibido se é possível a realização na realidade? A indústria do entretenimento, movida cegamente pela lógica do lucro, não tem receios de veicular o que

46 BENJAMIN, (2017). 
for, desde que seja lucrativo. "A obra se torna um veículo da psicologia do contemplador" ${ }^{\prime 47}$. Na repetição dos clichês e dos estereótipos, ao invés de trazer o novo, ela reforça os comportamentos já dados, daí seu caráter conformista. No grande leque de opções ofertadas, as reações idiossincráticas encontram eco nessas manifestações planejadas para satisfazê-las.

Só em uma arte diferenciada, como a música de Schönberg, por exemplo, "a mimese se conjuga com a racionalidade sem recaídas" 48 ela permite que abdiquemos de nossos esquemas mentais para nos abandonarmos a algo novo e voltarmos diferentes, mais ricos em experiência. A filosofia ao ser a autoconsciência da eterna defasagem entre o que dizemos, significamos, do mundo e do outro, e esses como são em si mesmos, também permite a revisão dos comportamentos compulsivos, a introdução da dúvida no excesso de coerência dos esquemas autoritários.

\section{Considerações Finais}

Portanto a estética de Adorno mantêm uma ambivalência fundamental, talvez ainda não superada, pois, por um lado, vê a arte entregue a lógica do capital utilizando inclusive das idiossincrasias inconscientes das pessoas para lhes vender o produto. Por outro, enquanto mônada que possui uma linguagem própria, resultado da necessidade da expressão da subjetividade, a arte ainda mantém a possibilidade de modificação da própria subjetividade e suas vivências.

\section{Referências}

ADORNO, Theodor W. Dialética Negativa. Tradução Marco Antonio Casanova. Rio de janeiro: Zahar, 2009.

\footnotetext{
47 ADORNO, (2004, p. 31).

48 ADORNO, (2004,p. 35).
} 
ADORNO, Theodor W. Teoría Estética. Traducción de Jorge Navarro Pérez. Madrid: Akal, 2004.

ADORNO, Theodor W . Anotações sobre Kafka. In: Prismas. Tradução de Augustin Wernet e Jorge de Almeida. São Paulo: Ática, 2001.

ADORNO, Theodor W . Kierkegaard: Construcción de lo estético. Traducción de Joaquín Mielke. Madrid: Akal, 2006.

ADORNO, Theodor W. Três estudos sobre Hegel. Trad. Ulisses Vaccari. SP: Editora da Unesp, 2013.

ADORNO, Theodor W. Palavras e sinais: modelos críticos 2. Trad. Maria Helena Ruschel. RJ: Petrópolis: Vozes, 1995

ADORNO, Theodor W. Ensaios sobre psicologia social e psicanálise. Trad. Verlaine Freitas. São Paulo: Editora da Unesp, 2015.

ADORNO, T.; HORKHEIMER, M. Dialética do esclarecimento: fragmentos filosóficos. Trad. Guido Antonio de Almeida. Zahar: 1985.

BENJAMIN, Walter. Magia e técnica, arte e política. Ensaios sobre literatura e história da cultura. Trad. Sergio Paulo Rouanet. São Paulo: Brasiliense, 1994.

BENJAMIN, Walter. A obra de arte na época da possibilidade de sua reprodução técnica. In: BENJAMIN, Walter. Estética e Sociologia da Arte. Trad. João Barrento. Belo Horizonte: Autêntica, 2017. Edição do Kindle. p. 228-1063. https://doi.org/10.17851/2179-8478.13.2.295-313

BERNSTEIN, Jay. Negative Dialektik. Begriff und Kategorien III. Adorno zwischen Kant und Hegel. In: HONNETH, A.; MENKE, C. H. (org.) Theodor W. Adorno: negative dialektik. Berlin: Akademie Verlag, 2006. p. 89-119 https:// doi.org/10.1524/9783050050201.89

KAFKA, F. A metamorfose. Trad. Modesto Carone. São Paulo: Companhia das Letras, 1997.

KANT. Crítica da Faculdade do juízo. Trad. Valério Rohden e António Marques. RJ: Forense Universitária, 2005.

GAGNEBIN, Jeanne Marie. Limiar, aura e rememoração. São Paulo: Editora 34, 2014. https://doi.org/10.34024/limiar.2016.v3.9237

GAGNEBIN, Jeanne Marie. Do conceito de mímesis no pensamento de Adorno e Benjamin. Perspectivas: Revista de Ciências Sociais, São Paulo, v. 16, p. 67-86, 1993. 
HEGEL, G. W. F. Fenomenologia do espírito. Trad. Paulo Menezes e Karl-Heiz Efken. Petrópolis: Vozes, 1992.

SOMMER, Marc Nicolas. Das Konzept einer negativen Dialektik: Adorno und Hegel. Tübingen: Mohr Siebeck, 2016. https://doi.org/10.1628/978-3-16154187-2

STEIN, Swen. Der Begriff der Mimesis in der Ästhetischen Theorie Adornos. Berlin: Edoc.hu-berlin.de (Humboldt-Universität zu Berlin), 2008, p. 1-10. Disponível em: https://edoc.hu-berlin.de/handle/18452/8077. Acesso em: 29 jul. 2018. https://doi.org/10.1515/9783050071435-001

WELLMER, Albrecht. Truth, semblance, reconciliation: Adorno's aesthetic redemption of modernity. New York: Telos Press, 1986. Disponível em: http:// journal.telospress.com/content/1984/62/89.abstract. Acesso em: 20 jul. 2018. https://doi.org/10.3817/1284062089

WELLMER, Albrecht. Modell3: Meditationen zur Metaphysik: Metaphysik im Augenblick ihres Sturzes. In: HONNETH, A.; MENKE, CH. (org.) Theodor W. Adorno: negative dialektik. Berlin: Akademie Verlag, 2006. p. 189-207 https:// doi.org/10.1524/9783050050201.189

WELLMER, Albrecht. Acerca da negatividade e autonomia da arte. Sobre a atualidade da estética de Adorno. Revista Tempo Brasileiro, Rio de Janeiro, n. 155, p. 27-55, out. / dez., Rio de Janeiro, 2003. https://doi.org/10.31254/ sportmed.1202

WELLMER, Albrecht. Sobre la dialéctica de modernidade e post modernidade: la crítica de la razón después de Adorno. Tradución de José Luiz Arantégui. Madrid: Gráficas Rógar, 1993 https://doi.org/10.2307/j.ctvm7bcdz.13

\section{Endereço Postal}

E-mail: sarapozzer@gmail.com

Universidade Federal de Mato Grosso, Instituto de Ciências Humanas e Sociais, Departamento de Filosofia. Universidade Federal de Mato Grosso, Boa Esperança, 78060900 - Cuiabá, MT - Brasil Telefone: (65) 36158000 